\title{
A broad-host-range CRISPRi toolkit for silencing gene expression in Burkholderia
}

Andrew M. Hogan ${ }^{1}$, A. S. M. Zisanur Rahman ${ }^{1}$, Tasia J. Lightly ${ }^{1}$, Silvia T. Cardona ${ }^{1,2^{*}}$.

${ }^{1}$ Department of Microbiology, University of Manitoba, Winnipeg, MB, Canada.

${ }^{2}$ Department of Medical Microbiology \& Infectious Diseases, University of Manitoba, Winnipeg, Canada.

*To whom correspondence should be addressed: Silvia.Cardona@umanitoba.ca 


\section{Supplemental material:}

Supplemental Tables 1-3 are provided here

Supplemental Tables 4 and 5 are provided as a separate Excel file.

Supplemental Figures 1-10 are provided here

Supplemental Table 1: Bacterial strains and plasmids used in this work.

\begin{tabular}{|c|c|c|}
\hline Strain or plasmid & Features & Source \\
\hline $\begin{array}{l}\text { Burkholderia cenocepacia } \\
\text { K56-2 }\end{array}$ & $\begin{array}{l}\text { Clinical isolate from cystic } \\
\text { fibrosis patient; ET12 lineage }\end{array}$ & (Darling et al., 1998) \\
\hline K56-2::CTX1-rha & $\begin{array}{c}\text { Derived from K56-2; pAH-CTX1- } \\
\text { rha integrated at attB site; clean } \\
\text { deletion of plasmid accessory } \\
\text { genes }\end{array}$ & This study \\
\hline K56-2::dCas9 & $\begin{array}{l}\text { Derived from K56-2; pAH-CTX1- } \\
\text { rhadCas9 integrated at attB site; } \\
\text { clean deletion of plasmid } \\
\text { accessory genes }\end{array}$ & This study \\
\hline K56-2::dCas9-native & $\begin{array}{l}\text { Derived from K56-2; pAH-CTX1- } \\
\text { rhadCas9-native integrated at attB } \\
\text { site; clean deletion of plasmid } \\
\text { accessory genes }\end{array}$ & This study \\
\hline K56-2 fliF::pAH26 & $\begin{array}{l}\text { Derived from K56-2; pAH26 } \\
\text { integrated into fliF; } \mathrm{Tp}^{\mathrm{r}}\end{array}$ & This study \\
\hline K56-2 phbC::pAH27 & $\begin{array}{l}\text { Derived from K56-2; pAH27 } \\
\text { integrated into fliF; } \mathrm{Tp}^{\mathrm{r}}\end{array}$ & This study \\
\hline K56-2 $\triangle p a a A B C D E$ & $\begin{array}{l}\text { Derived from K56-2; clean } \\
\text { deletion of the paaABCDE operon }\end{array}$ & (Pribytkova et al., 2014) \\
\hline $\begin{array}{l}\text { Burkholderia multivorans } \\
\text { ATCC } 17616\end{array}$ & Soil sample & ATCC \\
\hline ATCC 17616::dCas9 & $\begin{array}{l}\text { Derived from ATCC 17616; pAH- } \\
\text { CTX1-rhadCas9 integrated at attB } \\
\text { site; clean deletion of plasmid } \\
\text { accessory genes }\end{array}$ & This study \\
\hline $\begin{array}{l}\text { Burkholderia thailandensis } \\
\text { E264 }\end{array}$ & Rice-field soil sample in Thailand & DSMZ \\
\hline
\end{tabular}




\begin{tabular}{|c|c|c|}
\hline E264::dCas9 & $\begin{array}{l}\text { Derived from ATCC E264; pAH- } \\
\text { CTX1-rhadCas9 integrated at attB } \\
\text { site; clean deletion of plasmid } \\
\text { accessory genes }\end{array}$ & This study \\
\hline E. coli $\mathrm{DH} 5 \alpha$ & $\begin{array}{c}\mathrm{F}^{-} \text {Ф80lacZ } \Delta \mathrm{M} 15 \Delta(\text { lacZYA- } \\
\text { argF) U169 recA1 endA1 hsdR17 } \\
\left(\mathrm{r}_{\mathrm{H}}^{-}, \mathrm{m}_{\mathrm{K}}^{+}\right) \text {phoA sup } \mathrm{E} 44 \lambda^{-} \text {thi-1 } \\
\text { gyrA96 relA1 }\end{array}$ & Cardona lab collection \\
\hline E. coli SY327 & $\begin{array}{c}\mathrm{F}^{-} \text {araD } \Delta(\text { lac-proAB) argE }(\mathrm{Am}) \\
\text { recA56 Rifr nalA } \lambda \text { pir }\end{array}$ & (Miller and Mekalanos, 1988) \\
\hline E. coli $\mathrm{MM} 290$ & 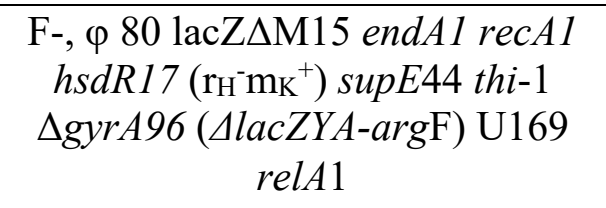 & Cardona lab collection \\
\hline mini-CTX1 & $\begin{array}{c}\text { Tet }^{\mathrm{r}}, \Omega \text {-FRT-attPMCS, ori } \mathrm{p}_{\mathrm{pB}} 1 \\
\text { int }_{\varphi \mathrm{CTX}}, \text { and oriT }\end{array}$ & (Hoang et al., 2000) \\
\hline pKD3 & $\mathrm{Cm}^{\mathrm{r}} \operatorname{rgnB}$ ori $_{\mathrm{R} 6 \mathrm{~K}}$ & (Datsenko and Wanner, 2000) \\
\hline pAH18 & $\begin{array}{c}\text { Derived from pGPI-SceI; ori } i_{R 6 K} \\
\mathrm{Tp}^{\mathrm{r}} \mathrm{mob}^{+} \text {carries I-SceI gene; } 475 \\
\text { bp from both upstream and } \\
\text { downstream flanking regions } \\
\text { between the } F R T \text { sites on pAH- } \\
\text { CTX1-rhadCas9 cloned between } \\
\text { KpnI and EcoRI sites }\end{array}$ & This study \\
\hline pHA25-SceI & $\begin{array}{l}\text { Derived from pDAI-SceI; ori }{ }_{\mathrm{pBBR} 1} \\
\mathrm{Cm}^{\mathrm{r}} \mathrm{mob}^{+} \mathrm{P} \text { dhfr I-SceI; cat gene } \\
\text { from pKD3 cloned into AgeI and } \\
\text { XhoI sites }\end{array}$ & This study \\
\hline pFLPe4 & $\begin{array}{c}\mathrm{Ap}^{\mathrm{r}} \mathrm{Km}^{\mathrm{r}} \text { oriT ori } \text { orO1600-rep }\left(\mathrm{Ts}_{\mathrm{BBt}}\right) \\
\text { rhaR rhaS } P_{\text {rhaB }}\end{array}$ & (Choi et al., 2008) \\
\hline pAH26 & $\begin{array}{c}\text { pGPQ-TP with } 330 \text { bp 5 } \\
\text { fragment of } B \text {. cenocepacia } \mathrm{K} 56-2 \\
\text { fliF cloned between KpnI and } \\
\text { EcoRI sites }\end{array}$ & This study \\
\hline pAH27 & $\begin{array}{c}\text { pGP } \Omega \text {-TP with } 335 \text { bp } 5 \\
\text { fragment of } B . \text { cenocepacia } \mathrm{K} 56-2 \\
\text { phbC cloned between } K p n \text { I and } \\
\text { EcoRI sites }\end{array}$ & This study \\
\hline
\end{tabular}




\begin{tabular}{|c|c|c|}
\hline pAH-CTX1-rha & $\begin{array}{l}\text { Derived from mini-CTX1; rhaS } \\
\text { rhaR } \mathrm{P}_{\text {rhas }} \text { from pSC201 cloned } \\
\text { into SpeI and HindIII sites }\end{array}$ & This study \\
\hline pAH-CTX1-rhadCas9 & $\begin{array}{l}\text { Derived from pAH-CTX1-rha; } \\
\text { codon-optimized dcas } 9 \text { cloned } \\
\text { into SpeI and NotI sites }\end{array}$ & This study \\
\hline pAH-CTX1-rhadCas9-native & $\begin{array}{c}\text { Derived from pAH-CTX1-rha; } \\
\text { native } d \text { cas } 9 \text { cloned into SpeI and } \\
\text { NotI sites }\end{array}$ & This study \\
\hline pSCrhaB2 & $\underset{\substack{o i_{\mathrm{pBBR} 1} r h a R, r h a S, P_{r h a B} \mathrm{Tp}^{\mathrm{R}} \\
m o b^{+}}}{ }$ & (Cardona and Valvano, 2005) \\
\hline pSCrhaB2-sgRNA & $\begin{array}{l}\text { Derived from pSCrhaB2; gRNA } \\
\text { cassette from pgRNA-bacteria } \\
\text { cloned into KpnI and EcoRI sites }\end{array}$ & This study \\
\hline pSCB2-sgRNA & $\begin{array}{l}\text { Template for pgRNA created by } \\
\text { inverse PCR; derived from } \\
\text { pSCrhaB2-sgRNA by inverse } \\
\text { PCR to remove rhaS, rhaR, and } \\
\mathrm{P}_{\text {rhaB }}\end{array}$ & This study \\
\hline pgRNA-guideless & $\begin{array}{l}\text { Derived from pSCB2-sgRNA; } 20 \\
\text { nt binding region of gRNA } \\
\text { removed by inverse PCR }\end{array}$ & This study \\
\hline pgRNA-non-target & $\begin{array}{l}\text { Derived from pSCB2-sgRNA; } \\
\text { random } 20 \mathrm{nt} \text { sequence added as } \\
\text { gRNA binding region by inverse } \\
\text { PCR }\end{array}$ & This study \\
\hline pgRNA1-23 & $\begin{array}{l}\text { Derived from pSCB2-sgRNA by } \\
\text { inverse PCR to add new } 20 \mathrm{nt} \\
\text { gRNA binding region; see } \\
\text { Supplementary Table } 4 \text { for details }\end{array}$ & This study \\
\hline pSC-rhadCas9 & $\begin{array}{l}\text { Derived from pSCrhaB2; codon- } \\
\text { optimized dcas } 9 \text { was cloned into } \\
\text { NdeI and HindIII cites }\end{array}$ & This study \\
\hline pDAI-SceI & ori $_{p B B R 1}$ Tet $^{\mathrm{r}} \mathrm{mob}^{+} \mathrm{P} d h$ fr I-SceI & (Flannagan et al., 2008) \\
\hline pGPI-SceI & $\begin{array}{c}\text { ori }_{\text {R6K }} \mathrm{Tp}^{\mathrm{r}} \mathrm{mob}^{+} \text {carries I-SceI } \\
\text { gene }\end{array}$ & (Flannagan et al., 2008) \\
\hline pGP $\Omega-T p$ & ori ${ }_{\mathrm{R} 6 \mathrm{~K}}, \Omega \mathrm{Tp}^{\mathrm{r}}, \mathrm{mob}^{+}$ & (Flannagan et al., 2007) \\
\hline
\end{tabular}




\begin{tabular}{|c|c|c|}
\hline pRK2013 & $\begin{array}{c}\text { oricolE1 RK2 derivative } \text { Kan }^{\mathrm{r}} \text { mob }^{+} \\
\operatorname{tra}^{+}\end{array}$ & (Figurski and Helinski, 1979) \\
\hline pSC201 & ori 6 $6 \mathrm{~K}$ rhaR rhaS $P_{\text {rhaB }}$ dhfr & (Ortega et al., 2007) \\
\hline
\end{tabular}


Supplemental Table 2. Primers used in this work.

\begin{tabular}{|c|c|}
\hline Primer Number & Sequence (restriction sites in lowercase) \\
\hline 153 & GTGGATGACCTTTTGAATGACCTTT \\
\hline 154 & ACAGGAACACTTAACGGCTGACATG \\
\hline 781 & TAAGATggatccTCAGTTGGCTTCATCGCTAC \\
\hline 847 & TTCCTGTCAGTAACGAGAAGG \\
\hline 848 & CCGCCAGGCAAATTCTGTTT \\
\hline 954 & GGGTTCTATCGCCACGGAC \\
\hline 955 & ATTTTTGCGGCGCGTGTAG \\
\hline 957 & GTCAGCAATTTCGCCAGCAG \\
\hline 976 & TATAATAaagcttATGTCAACTGGGTTCGTGC \\
\hline 979 & TATATAaagcttACGCAGAAAGGCCCACCCGAAG \\
\hline 987 & AAATTAcatatgGACAAGAAGTACTCGATCGGCC \\
\hline 1008 & GTTTCCTCAACGACCTGCAG \\
\hline 1025 & ATAATAggtaccCGCACGAACCCAGTTGAC \\
\hline 1071 & ATAATAactagtTCCTGCTGAATTTCATTACGACC \\
\hline 1072 & ATAATAactagtTATGGACAAGAAGTACTCGATCGG \\
\hline 1073 & ATAATAgcggccgcACGCAGAAAGGCCCACCCGAAG \\
\hline 1074 & AAGTGGATCAGCAAGGACGG \\
\hline 1075 & AAGTCCTGAGCGCCTACAAC \\
\hline 1077 & CCGTGCCATGTTCGACAATC \\
\hline 1084 & ATAATActcgagCGCCTACCTGTGACGGAAGA \\
\hline
\end{tabular}




\begin{tabular}{|c|c|}
\hline 1091 & ACTGCCTACCCCACAACAAC \\
\hline 1126 & TCGTTGCGCAGATAGGTCAC \\
\hline 1128 & GATCGATCCTACCCCTTGCG \\
\hline 1129 & GCCTAAGGTGCTTGTTCGTC \\
\hline 1150 & AATTAAaccggtACTCATCGCAGTACTGTTGTATTC \\
\hline 1156 & TAAGATggtaccTTCCCTACAAGTTCGCCGATG \\
\hline 1157 & TAAGATgaattcGGGTAGAGGTCGACGAACAC \\
\hline 1167 & CTGCCGTTCGAGTTCATGC \\
\hline 1168 & CGGTTACAATGCTCGACCTTG \\
\hline 1194 & AGGGCTTCATGACGGGTTTC \\
\hline 1195 & TCGGTATCTCTGGCTGTTCG \\
\hline 1196 & ATAATAggtaccCGTTCCAGATGCCGTCGATG \\
\hline 1197 & ATAATAgaattcGTGAAACGGATGCGCTCAC \\
\hline 1216 & ATAATAactagtTATGGATAAGAAATACTCAATAGGCT1 \\
\hline 1217 & ATAATAgcggccgcACGCAGAAAGGCCCAC \\
\hline 1218 & CTTCCGCTGTCTCTCCACTG \\
\hline 1219 & GTAAACGGATGCTGGCTAGTG \\
\hline
\end{tabular}


Supplemental Table 3. Inverse PCR primers (to introduce gRNAs) and colony PCR primers used in this work.

\begin{tabular}{|c|c|c|}
\hline $\begin{array}{l}\text { Primer } \\
\text { Number }\end{array}$ & Sequence & Purpose \\
\hline 848 & CCGCCAGGCAAATTCTGTTT & $\begin{array}{c}\text { Reverse primer for colony PCR, } \\
\text { all gRNAs }\end{array}$ \\
\hline 1092 & ACTAGTATTATACCTAGGACTGAGCTAGC & Reverse primer, all gRNAs \\
\hline 1093 & $\begin{array}{c}\text { GTTTTAGAGCTAGAAATAGCAAGTTAAAATAA } \\
\text { GGC }\end{array}$ & Forward primer, control gRNA \\
\hline 1095 & $\begin{array}{l}\text { GCGGGACGACTGAGCTCGCTGTTTTAGAGCTA } \\
\text { GAAATAGCAAGTTAAAATAAGGC }\end{array}$ & $\begin{array}{l}\text { Forward primer, gRNA } 9 \text { for } \\
\text { targeting } f l i F \text { in } \mathrm{K} 56-2\end{array}$ \\
\hline 1096 & $\begin{array}{l}\text { CACGATGCGATTATCGTGACGTTTTAGAGCTAG } \\
\text { AAATAGCAAGTTAAAATAAGGC }\end{array}$ & $\begin{array}{l}\text { Forward primer, gRNA } 10 \text { for } \\
\text { targeting } f l i F \text { in } \mathrm{K} 56-2\end{array}$ \\
\hline 1097 & $\begin{array}{c}\text { CTCCGATCGACCGAAAAGAGGTTTTAGAGCTA } \\
\text { GAAATAGCAAGTTAAAATAAGGC }\end{array}$ & $\begin{array}{c}\text { Forward primer, gRNA } 11 \text { for } \\
\text { targeting } f l i F \text { in } \mathrm{K} 56-2\end{array}$ \\
\hline 1098 & GTATAATACTAGTGTTTTAGAGCTAGAAATAG & $\begin{array}{c}\text { Forward primer for colony PCR, } \\
\text { control gRNA }\end{array}$ \\
\hline 1100 & TAGGTATAATACTAGTGCGGGAC & $\begin{array}{l}\text { Forward primer for colony PCR, } \\
\text { gRNA } 9\end{array}$ \\
\hline 1101 & TAGGTATAATACTAGTCACGATGCG & $\begin{array}{l}\text { Forward primer for colony PCR, } \\
\text { gRNA } 10\end{array}$ \\
\hline 1102 & CCTAGGTATAATACTAGTCTCCGATC & $\begin{array}{l}\text { Forward primer for colony PCR, } \\
\text { gRNA } 11\end{array}$ \\
\hline
\end{tabular}




\begin{tabular}{|c|c|c|}
\hline 1161 & $\begin{array}{c}\text { GTCGGTTAATAAATTTGTTGGTTTTAGAGCTAG } \\
\text { AAATAGCAAGTTAAAATAAGGC }\end{array}$ & $\begin{array}{l}\text { Forward primer, gRNA } 1 \text { for } \\
\text { targeting paaA in } \mathrm{K} 56-2\end{array}$ \\
\hline 1162 & $\begin{array}{l}\text { GTATAAACCAACCGACCGGTGTTTTAGAGCTA } \\
\text { GAAATAGCAAGTTAAAATAAGGC }\end{array}$ & $\begin{array}{c}\text { Forward primer, K56-2 gRNA } 2 \\
\text { for targeting paaA in K56-2 }\end{array}$ \\
\hline 1163 & $\begin{array}{l}\text { CGAAGTATAAACCAACCGACGTTTTAGAGCTA } \\
\text { GAAATAGCAAGTTAAAATAAGGC }\end{array}$ & $\begin{array}{c}\text { Forward primer, K56-2 gRNA } 3 \\
\text { for targeting paaA in } \mathrm{K} 56-2\end{array}$ \\
\hline 1164 & TCCTAGGTATAATACTAC & $\begin{array}{l}\text { Forward primer for colony PCR, } \\
\text { gRNA } 1\end{array}$ \\
\hline 1165 & GTGTATAAACCAACCGACCGG & $\begin{array}{l}\text { Forward primer for colony PCR, } \\
\text { gRNA } 2\end{array}$ \\
\hline 1166 & CGAAGTATAAACCAACCGAC & $\begin{array}{l}\text { Forward primer for colony PCR, } \\
\text { gRNA } 3\end{array}$ \\
\hline 1171 & $\begin{array}{c}\text { CTCCAGATTCTGCCGCAGTGGTTTTAGAGCTAG } \\
\text { AAATAGCAAGTTAAAATAAGGC }\end{array}$ & $\begin{array}{l}\text { Forward primer, gRNA } 6 \text { and } 15 \\
\text { for targeting } p h b C \text { in K56-2 and } \\
\text { ATCC17616, respectively }\end{array}$ \\
\hline 1172 & $\begin{array}{c}\text { CGGGCCGTCATGCTCTGGAGGTTTTAGAGCTAG } \\
\text { AAATAGCAAGTTAAAATAAGGC }\end{array}$ & $\begin{array}{l}\text { Forward primer, gRNA } 7 \text { for } \\
\text { targeting } p h b C \text { in } \mathrm{K} 56-2\end{array}$ \\
\hline 1173 & $\begin{array}{c}\text { CGAGCCGGGCCGTCATGCTCGTTTTAGAGCTAG } \\
\text { AAATAGCAAGTTAAAATAAGGC }\end{array}$ & $\begin{array}{l}\text { Forward primer, gRNA } 8 \text { for } \\
\text { targeting } p h b C \text { in } \mathrm{K} 56-2\end{array}$ \\
\hline 1174 & $\begin{array}{l}\text { CCGTTCAGCCGGGCGTGTTCGTTTTAGAGCTAG } \\
\text { AAATAGCAAGTTAAAATAAGGC }\end{array}$ & $\begin{array}{l}\text { Forward primer, gRNA } 21 \text { for } \\
\text { targeting } p h b C \text { in E264 }\end{array}$ \\
\hline 1175 & $\begin{array}{c}\text { TTTCCTCGGTGTTGCCTGCGGTTTTAGAGCTAG } \\
\text { AAATAGCAAGTTAAAATAAGGC }\end{array}$ & $\begin{array}{l}\text { Forward primer, gRNA } 22 \text { for } \\
\text { targeting } p h b C \text { in E264 }\end{array}$ \\
\hline
\end{tabular}




\begin{tabular}{|c|c|c|}
\hline 1176 & $\begin{array}{l}\text { GTGGTTCCTCGGTGTTTCCTGTTTTAGAGCTAG } \\
\text { AAATAGCAAGTTAAAATAAGGC }\end{array}$ & $\begin{array}{l}\text { Forward primer, gRNA } 23 \text { for } \\
\text { targeting } p h b C \text { in E264 }\end{array}$ \\
\hline 1177 & $\begin{array}{l}\text { CGGGCCGTCATGCCCTGGAGGTTTTAGAGCTA } \\
\text { GAAATAGCAAGTTAAAATAAGGC }\end{array}$ & $\begin{array}{l}\text { Forward primer, gRNA } 16 \text { for } \\
\text { targeting } p h b C \text { in ATCC } 17616\end{array}$ \\
\hline 1178 & $\begin{array}{l}\text { CGAGCCGGGCCGTCATGCCCGTTTTAGAGCTA } \\
\text { GAAATAGCAAGTTAAAATAAGGC }\end{array}$ & $\begin{array}{l}\text { Forward primer, gRNA } 17 \text { for } \\
\text { targeting } p h b C \text { in ATCC } 17616\end{array}$ \\
\hline 1179 & GTCCTAGGTATAATACTAGTCTCCAG & $\begin{array}{l}\text { Forward primer for colony PCR, } \\
\text { gRNA } 6\end{array}$ \\
\hline 1180 & CCTAGGTATAATACTAGTCGGGC & $\begin{array}{l}\text { Forward primer for colony PCR, } \\
\text { gRNA } 7 \text { and } 16\end{array}$ \\
\hline 1181 & CCTAGGTATAATACTAGTCGAGCC & $\begin{array}{l}\text { Forward primer for colony PCR, } \\
\text { gRNA } 8 \text { and } 17\end{array}$ \\
\hline 1182 & GGTATAATACTAGTCCGTTCAGCC & $\begin{array}{l}\text { Forward primer for colony PCR, } \\
\text { gRNA } 21\end{array}$ \\
\hline 1183 & AGTCCTAGGTATAATACTAGTTTTCC & $\begin{array}{l}\text { Forward primer for colony PCR, } \\
\text { gRNA } 22\end{array}$ \\
\hline 1184 & GGTATAATACTAGTGTGGTTCCTC & $\begin{array}{l}\text { Forward primer for colony PCR, } \\
\text { gRNA } 23\end{array}$ \\
\hline 1198 & $\begin{array}{l}\text { CGACGAATGCCAAGCAGATAGTTTTAGAGCTA } \\
\text { GAAATAGCAAGTTAAAATAAGGC }\end{array}$ & $\begin{array}{l}\text { Forward primer, non-target } \\
\text { gRNA in all three species }\end{array}$ \\
\hline 1199 & CTAGGTATAATACTAGTCGACGAATGC & $\begin{array}{c}\text { Forward primer for colony PCR, } \\
\text { non-target gRNA }\end{array}$ \\
\hline
\end{tabular}




\begin{tabular}{|c|c|c|}
\hline 1200 & $\begin{array}{c}\text { TTAATAAATTTGTTGCGGAATTTGTTTTAGAGC } \\
\text { TAGAAATAGCAAGTTAAAATAAGGC }\end{array}$ & $\begin{array}{l}\text { Forward primer, gRNA } 12 \text { for } \\
\text { targeting paaA in ATCC } 17616\end{array}$ \\
\hline 1201 & $\begin{array}{c}\text { CGCAGTATAAACCAACCGACGTTTTAGAGCTA } \\
\text { GAAATAGCAAGTTAAAATAAGGC }\end{array}$ & $\begin{array}{l}\text { Forward primer, gRNA } 13 \text { for } \\
\text { targeting paaA in ATCC } 17616\end{array}$ \\
\hline 1202 & $\begin{array}{l}\text { ACATGGCGAGCGCTCTCGTCGTTTTAGAGCTAG } \\
\text { AAATAGCAAGTTAAAATAAGGC }\end{array}$ & $\begin{array}{l}\text { Forward primer, gRNA } 14 \text { for } \\
\text { targeting paaA in ATCC } 17616\end{array}$ \\
\hline 1203 & GTCCTAGGTATAATACTAGTTTAATAAATTTG & $\begin{array}{l}\text { Forward primer for colony PCR, } \\
\text { gRNA } 12\end{array}$ \\
\hline 1204 & GGTATAATACTAGTCGCAGTATAAAC & $\begin{array}{l}\text { Forward primer for colony PCR, } \\
\text { gRNA } 13\end{array}$ \\
\hline 1205 & GGTATAATACTAGTACATGGCGAG & $\begin{array}{l}\text { Forward primer for colony PCR, } \\
\text { gRNA } 14\end{array}$ \\
\hline 1206 & $\begin{array}{c}\text { CGGTTAATAAATGATTTTAGGTTTTAGAGCTAG } \\
\text { AAATAGCAAGTTAAAATAAGGC }\end{array}$ & $\begin{array}{l}\text { Forward primer, gRNA } 18 \text { for } \\
\text { targeting paaA in E264 }\end{array}$ \\
\hline 1207 & $\begin{array}{l}\text { GTTCACGCAGTATAAACCAAGTTTTAGAGCTA } \\
\text { GAAATAGCAAGTTAAAATAAGGC }\end{array}$ & $\begin{array}{l}\text { Forward primer, E264 gRNA } 19 \\
\text { for targeting paaA in E264 }\end{array}$ \\
\hline 1208 & $\begin{array}{l}\text { TGGCGATGTTCTCGTCCAGGGTTTTAGAGCTAG } \\
\text { AAATAGCAAGTTAAAATAAGGC }\end{array}$ & $\begin{array}{c}\text { Forward primer, E264 gRNA } 20 \\
\text { for targeting paaA in E264 }\end{array}$ \\
\hline 1209 & GGTATAATACTAGTCGGTTAATAAATGAT & $\begin{array}{l}\text { Forward primer for colony PCR, } \\
\text { gRNA } 18\end{array}$ \\
\hline 1210 & GGTATAATACTAGTGTTCACGCAG & $\begin{array}{l}\text { Forward primer for colony PCR, } \\
\text { gRNA } 19\end{array}$ \\
\hline
\end{tabular}




\begin{tabular}{|c|c|c|}
\hline 1211 & GTATAATACTAGTTGGCGATGTTC & Forward primer for colony PCR, \\
& & gRNA 20 \\
\hline 1212 & ACATGGCGAAGGCTCTCGTCGTTTTAGAGCTAG & Forward primer, gRNA 4 for \\
& AAATAGCAAGTTAAAATAAGGC & targating in K56-2 \\
\hline 1213 & ACGCAATCCCTCGACATCCCGTTTTAGAGCTAG & Forward primer, gRNA 5 for \\
& AAATAGCAAGTTAAAATAAGGC & targeting paaA in K56-2 \\
\hline 1214 & GGTATAATACTAGTACATGGCGAAG & Forward primer for colony PCR, \\
& gRNA 4 \\
\hline 1215 & GGTATAATACTAGTACGCAATCCC & Forward primer for colony PCR, \\
& & gRNA 5 \\
\hline
\end{tabular}

Supplemental Table 4 and 5 have been provided as a separate excel file. 

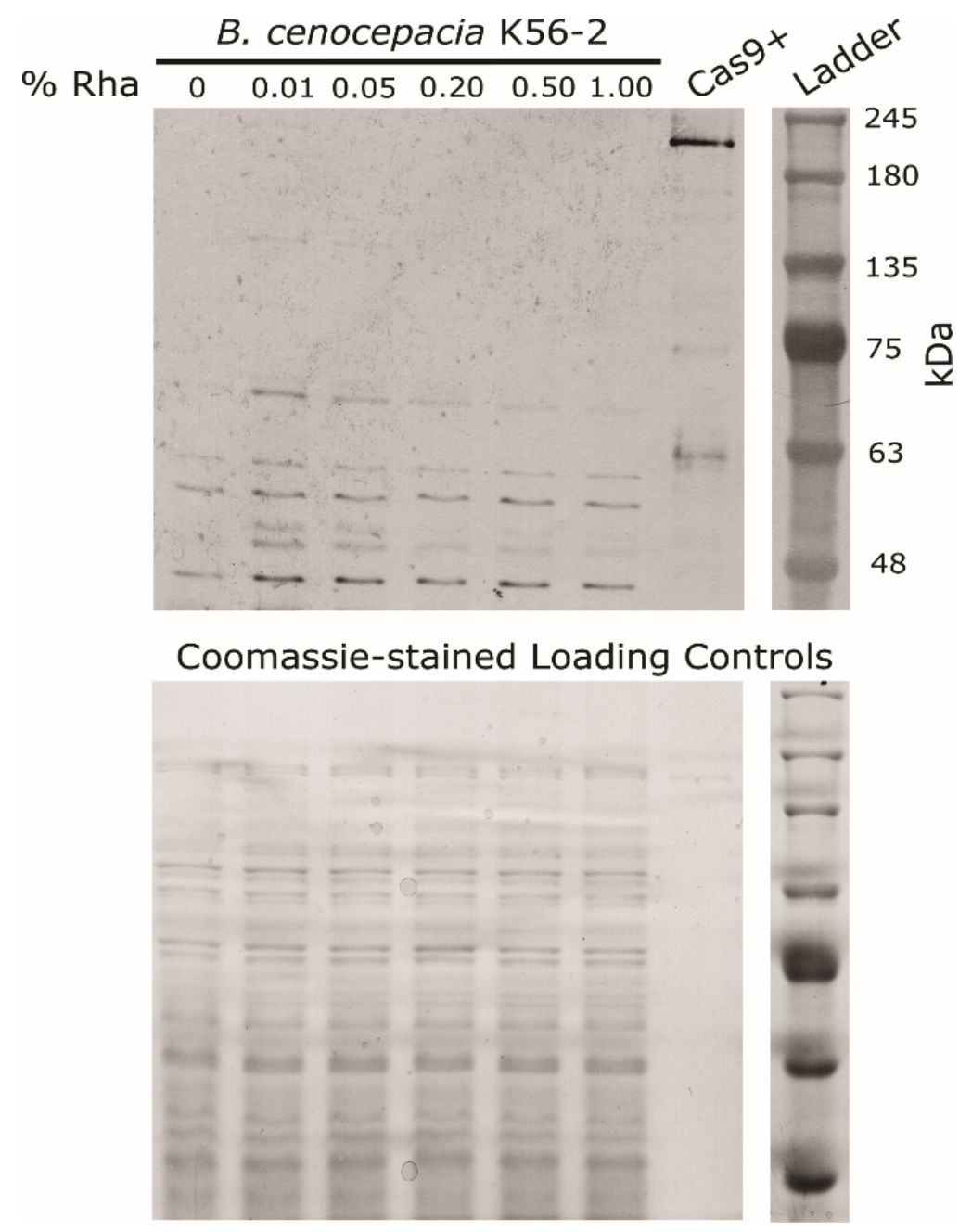

Supplemental Figure 1. The native dcas9 is not expressed in B. cenocepacia K56-2. $B$. cenocepacia $\mathrm{K} 56-2:: \mathrm{dCas} 9$-native was grown to $\mathrm{OD}_{600 \mathrm{~nm}} 0.6$ then induced for three hours with the indicated concentrations of rhamnose and the soluble protein fraction was extracted. dCas9 was detected with $\alpha$-Cas 9 antibodies. The lane labelled Cas9+ was loaded with 15 ng of purified Cas9. The Coomassie-stained gel run was in parallel to that used for immunoblotting to ensure equal loading. 


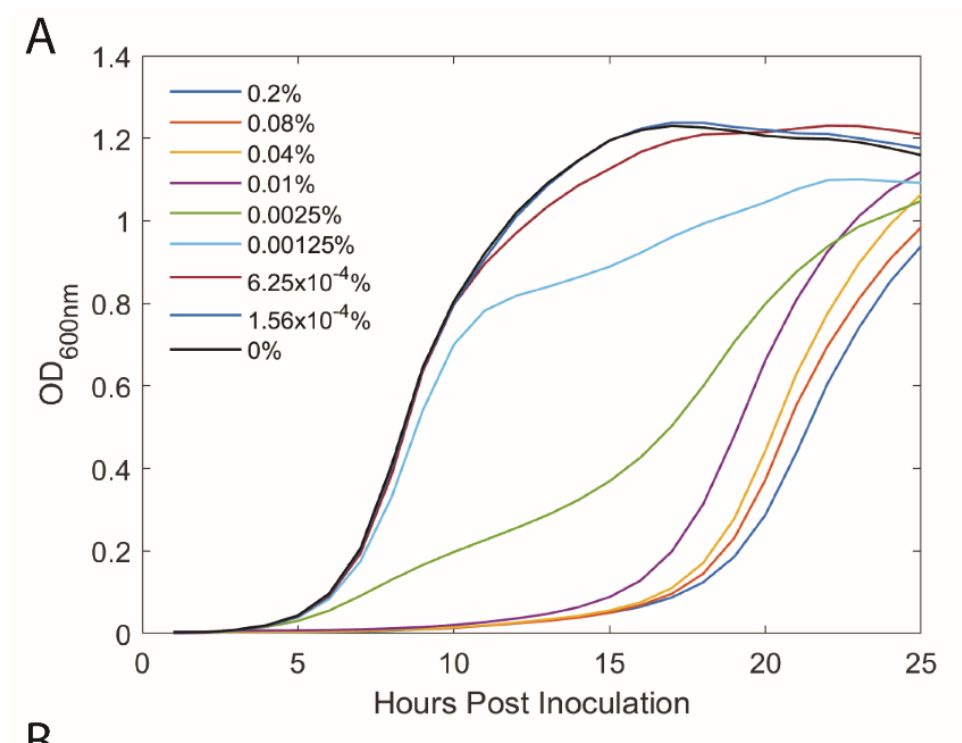

B

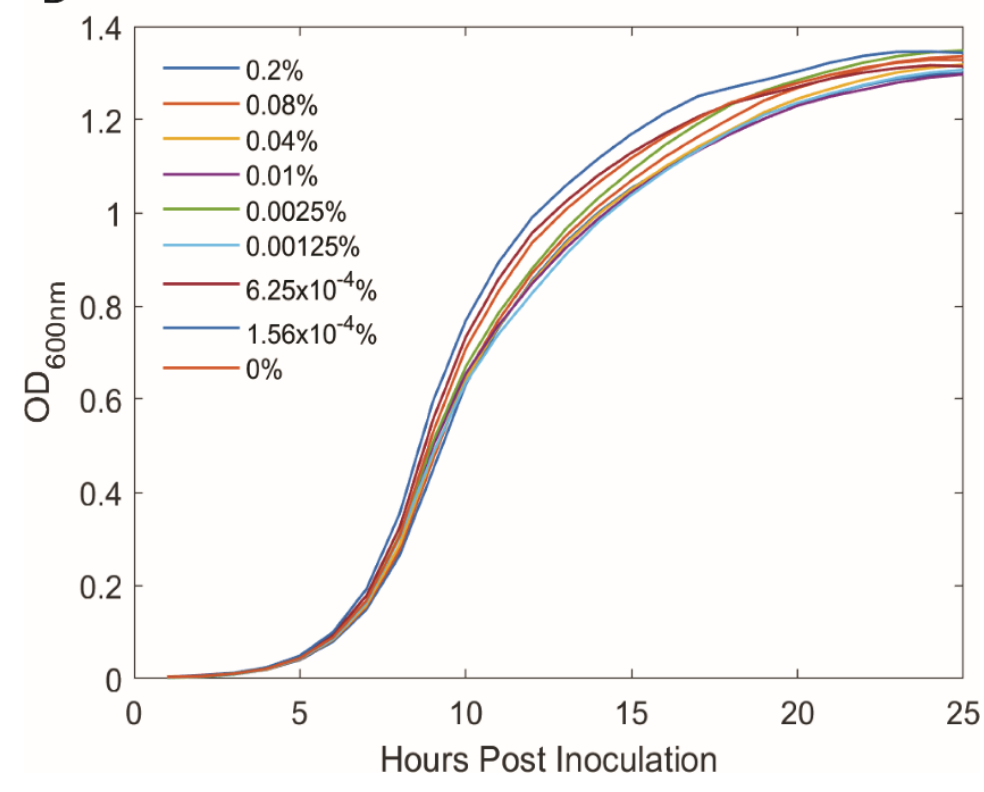

Supplemental Figure 2. dCas9 expressed from a multicopy plasmid causes a growth defect in B. cenocepacia K56-2. B. cenocepacia K56-2 harboring the plasmid pSC-rhadCas9 (A) or the vector control, pSCrhaB2 (B) was cultured with $100 \mu \mathrm{g} / \mathrm{mL}$ trimethoprim and with the indicated concentrations of rhamnose. 
A
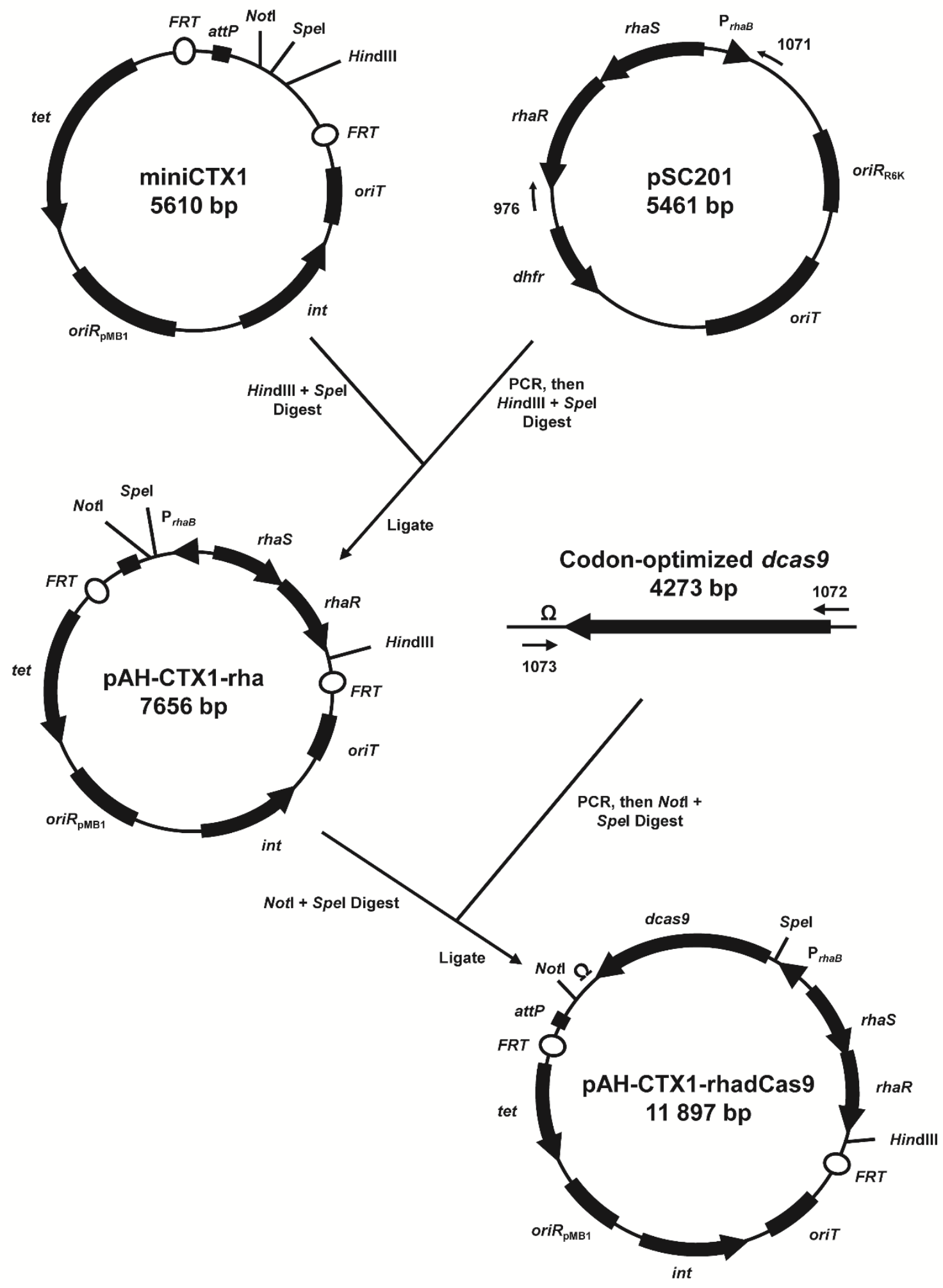


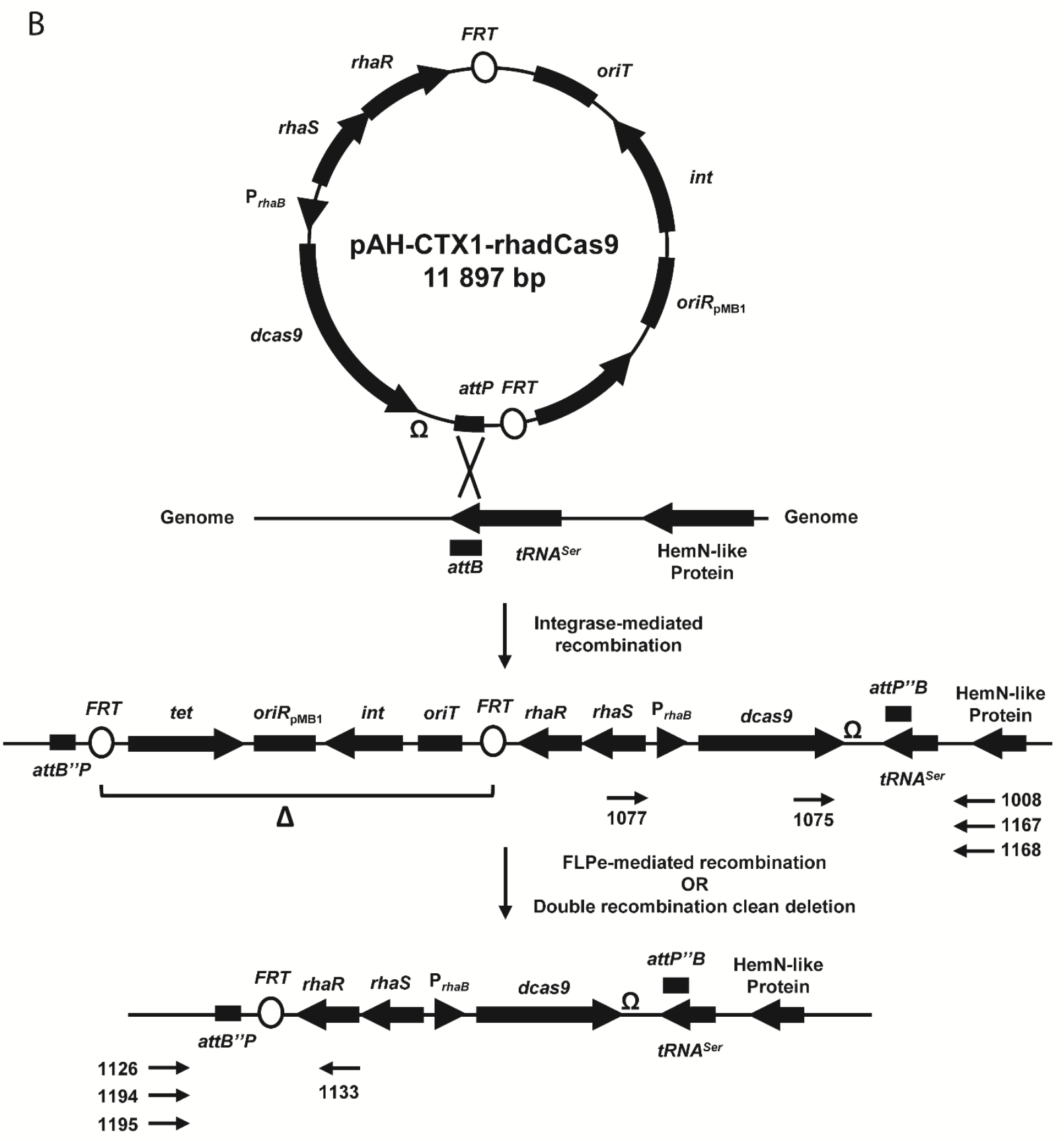

Supplemental Figure 3. Construction and insertion scheme for the integrative plasmids pAH-CTX1-rha and pAH-CTX1-rhadCas9. A) The rhamnose-inducible promoter was amplified from pSC201 with SpeI and HindIII restriction sites and introduced into mini-CTX1, creating pAH-CTX1-rha. The codon-optimized dcas 9 was constructed with flanking NotI and SpeI 
restriction sites as per Materials and Methods, and introduced into pAH-CTX1-rha, creating pAHCTX1-rhadCas9. B) pAH-CTX1-rha and pAH-CTX1-rhadcas9 integrate into the genome of a host organism at the attB site, usually located at the 3' end of the serine tRNA. Either FLPe of double homologous recombination can be used to remove the accessory genes, such as tet, creating an antibiotic-sensitive clean insertion mutant. Primer numbers used for cloning/colony PCR refer to the primer list found in Supplemental Table 2. 


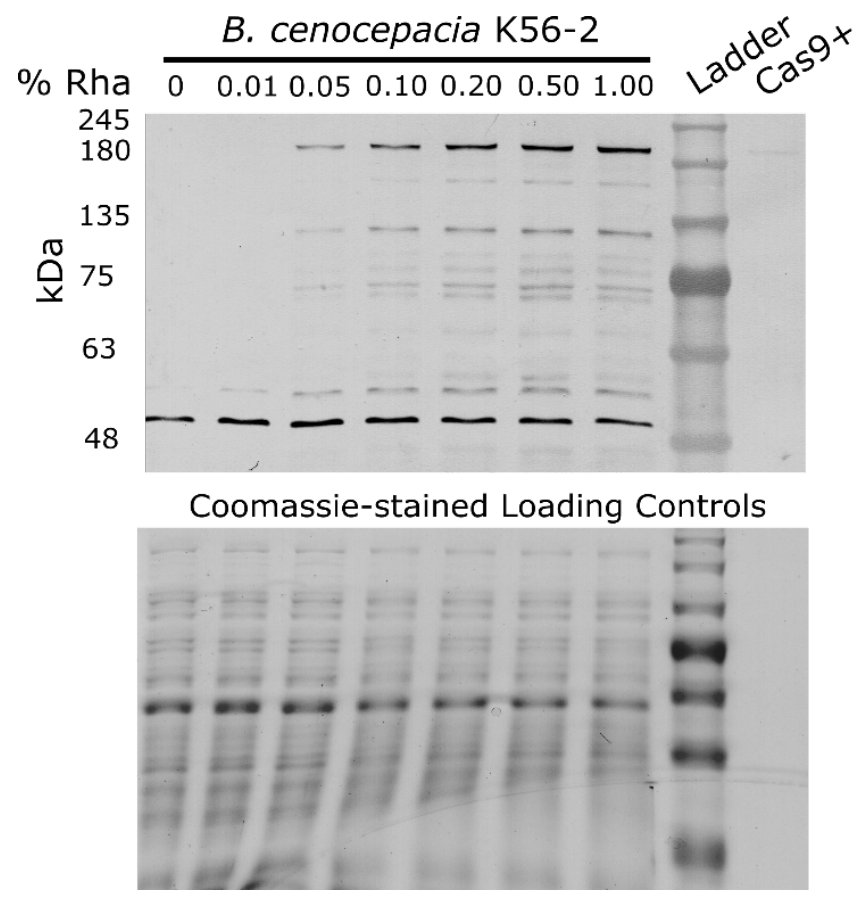

Supplemental Figure 4. Control experiments for the development of CRISPRi in Burkholderia. Entire immunoblot from Figure 1B and corresponding SDS-PAGE gel stained with Coomassie to demonstrate equal loading. The lane labelled Cas9+ was loaded with $15 \mathrm{ng}$ of purified Cas9. 


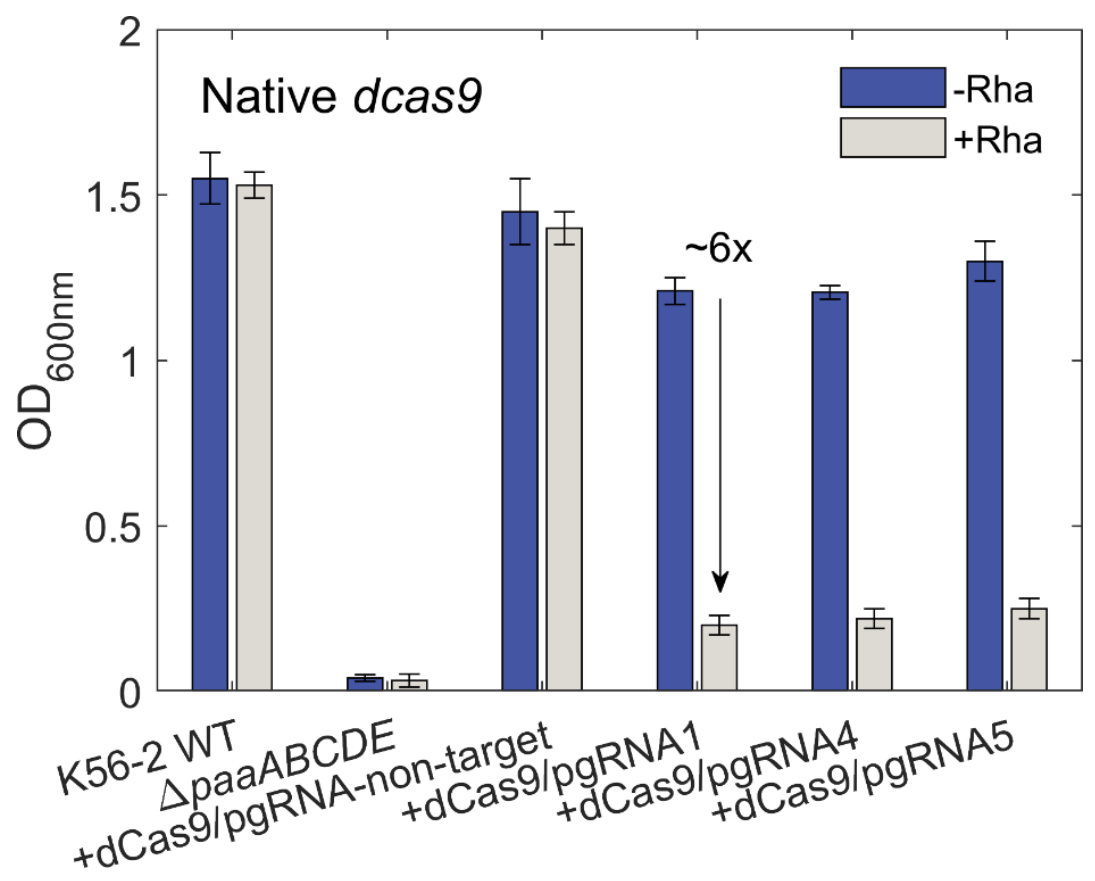

Supplemental Figure 5. Targeting paaA with CRISPRi using the native $d c a s 9$ yields moderate growth suppression in phenylacetic acid as the sole carbon source in B. cenocepacia K56-2. K56-2 WT, a mutant of the paaABCDE operon ( $\triangle p a a A B C D E)$, and $\mathrm{K} 56-2:: \mathrm{dCas} 9$ (+dCas9) harboring pgRNAs (as per Figure 2) were grown for 24 hours in minimal medium with PA (M9+PA) without (-Rha) or with $0.2 \%$ rhamnose (+Rha). All the values are the average of three independent biological replicates; error bars represent arithmetic mean $\pm \mathrm{SD}$. 


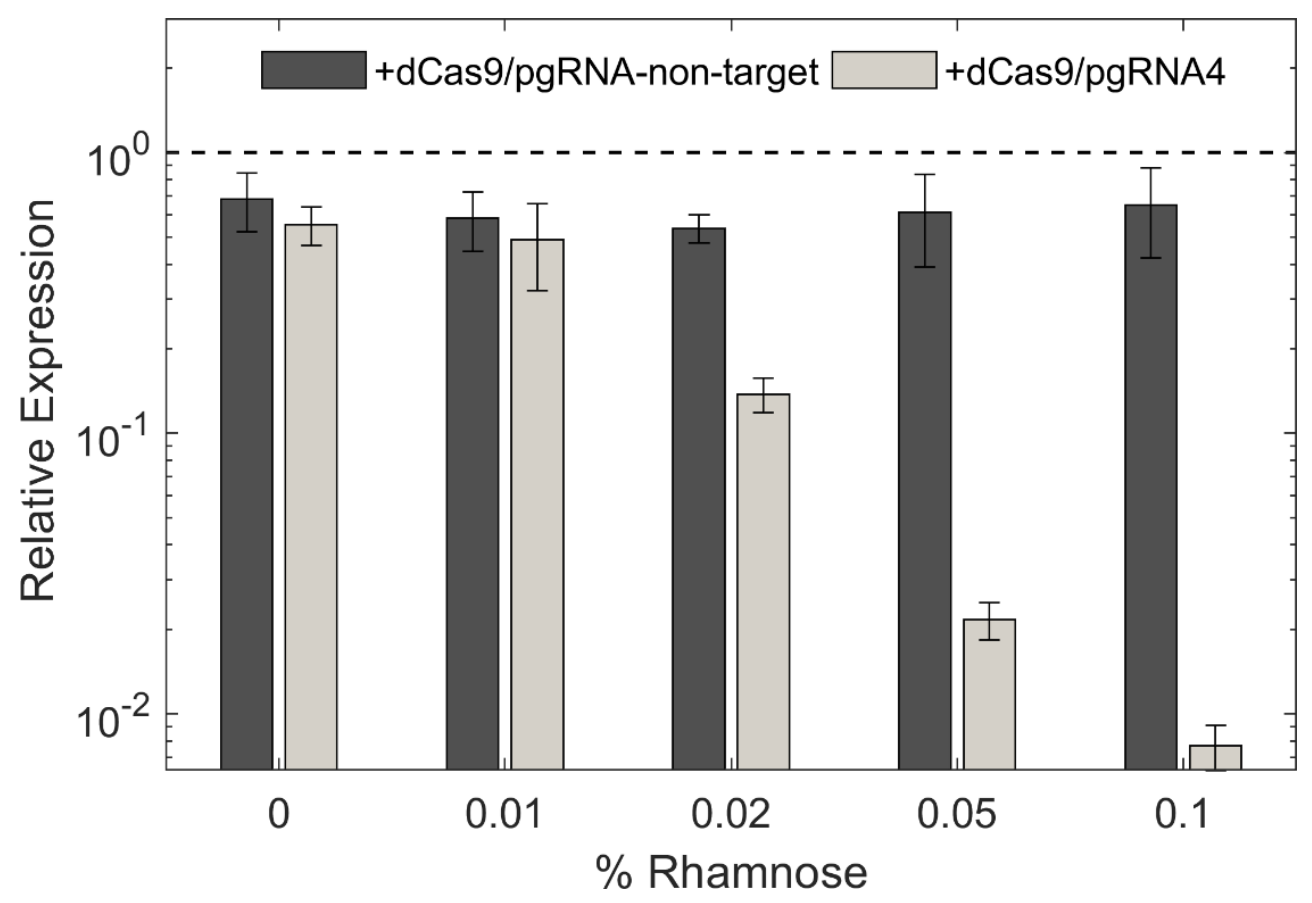

Supplemental Figure 6. CRISPRi repression of paaA mRNA expression is tunable. K56-2 WT, and K56-2::dCas9 (+dCas9) harboring pgRNAs (as per Figure 2) were grown overnight in LB with the specified concentration of rhamnose. Cells were subcultured also in rhamnose for 8 hours in LB, after which RNA was extracted and prepared for RT-qPCR. Expression of paaA is shown relative to WT (dashed line). Values are shown as mean $\pm \mathrm{SD}$ of three independent biological replicates. 


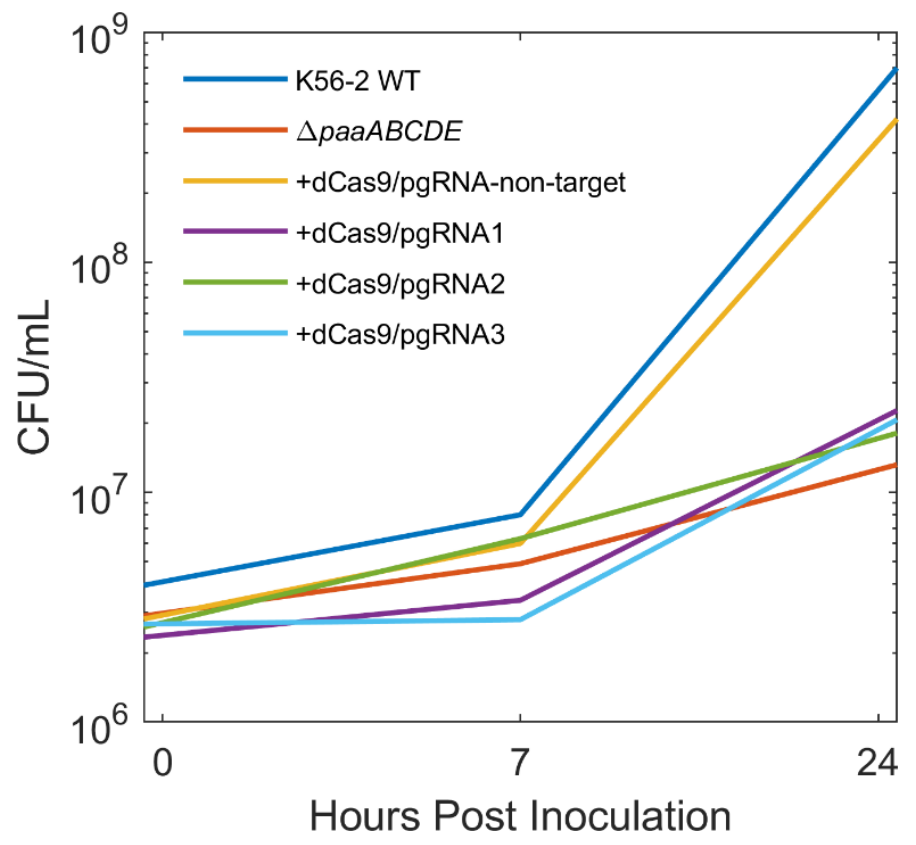

Supplemental Figure 7. Incubation in M9 with PA as the sole carbon source (M9+PA) does not reduce cell viability. $\mathrm{K} 56-2 \mathrm{WT}$, a mutant of the paaABCDE operon $(\triangle p a a A B C D E)$, and K56-2::dCas9 (+dCas9) harboring pgRNAs (as per Figure 2) were grown overnight in LB with $0.2 \%$ rhamnose, washed, and transferred to M9+PA. At the specified time points, cells were harvested and plated for $\mathrm{CFU} / \mathrm{mL}$ on rich medium. All values presented are the means of two independent biological replicates. 


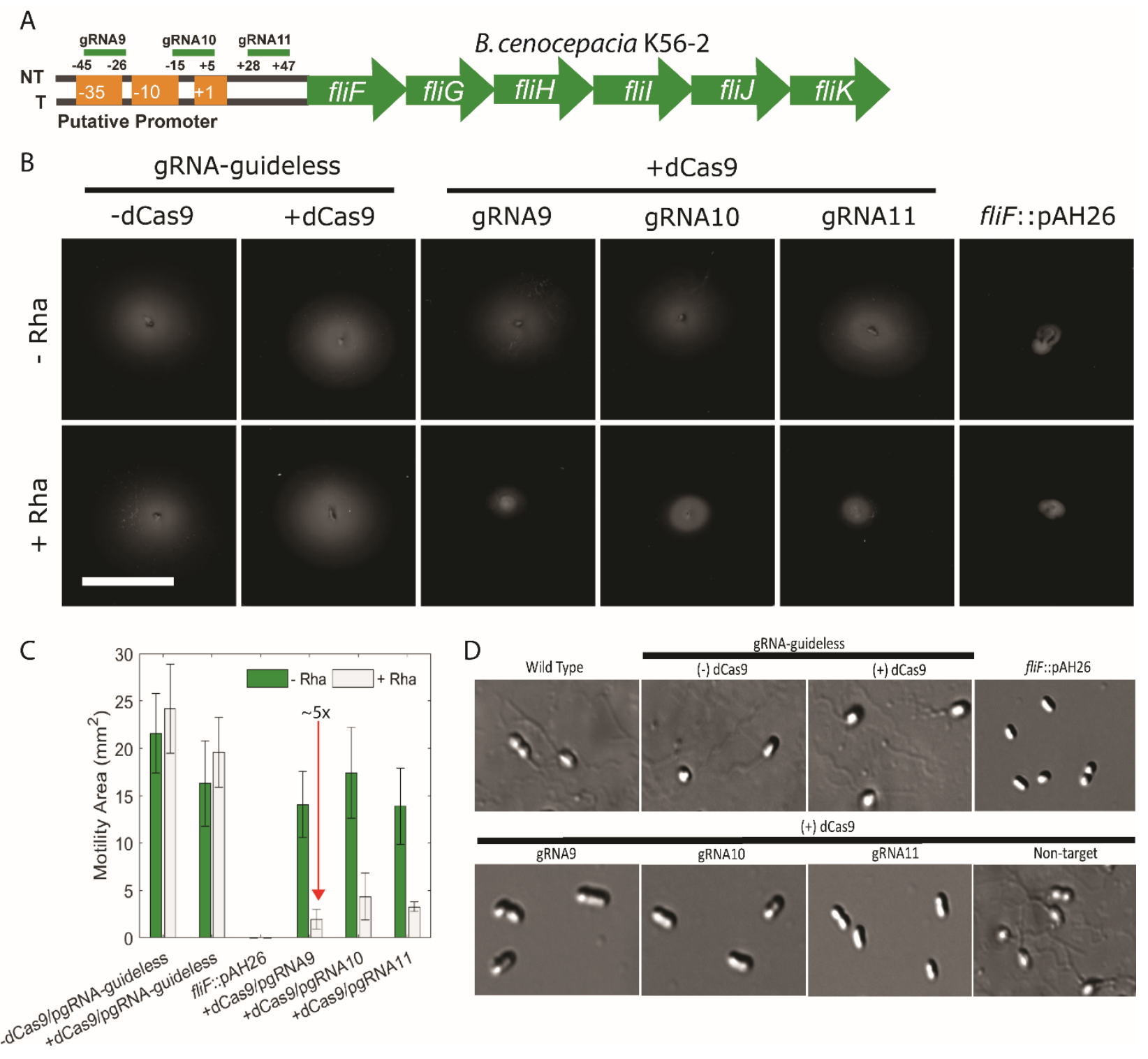

Supplemental Figure 8. Targeting fliF by CRISPRi in B. cenocepacia K56-2 reduces swimming motility. A) Positions of the gRNAs targeting regions upstream of the fliFGHIJK operon. gRNA9 and 10 were designed to target the promoter elements (-35 and -10 boxes), while gRNA11 targeted just upstream of the fliF ORF on the non-template (NT) strand. B) Motility was reduced, but not ablated by CRISPRi targeting of fliF. K56-2::CTX1-rha (-dCas9), K56-2::CTX1- 
rhadCas9 (+dCas9) (both harbouring pgRNA-guideless), and $+\mathrm{dCas} 9$ mutants harbouring gRNAs targeting $f l i F$ were stab inoculated into $0.3 \%$ agar nutrient broth medium containing $100 \mu \mathrm{g} / \mathrm{mL}$ trimethoprim and with or without $0.2 \%$ rhamnose. The scale bar is $2 \mathrm{~cm}$. C) Area of the swimming motility halos in B). D) The indicated strains were grown overnight with $0.2 \%$ rhamnose and 100 $\mu \mathrm{g} / \mathrm{mL}$ trimethoprim, as required, and used for flagellum staining. Cells were imaged by DIC as we found better contrast versus brightfield microscopy. 


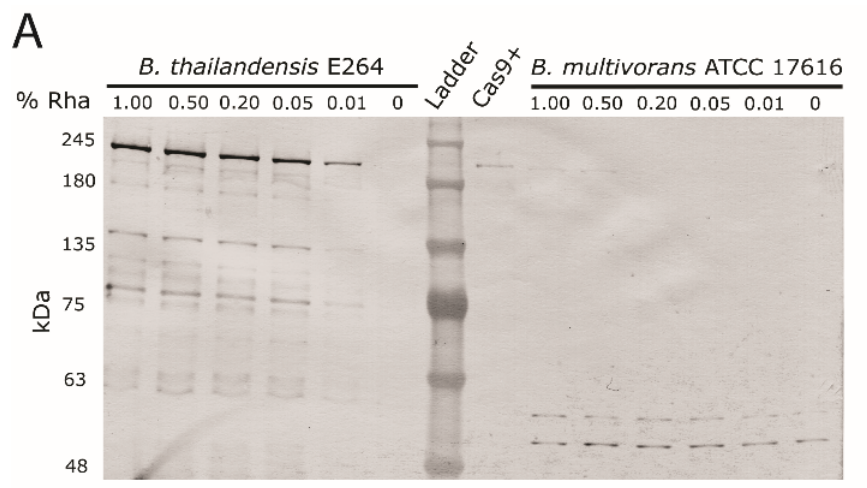

Coomassie-stained Loading Controls

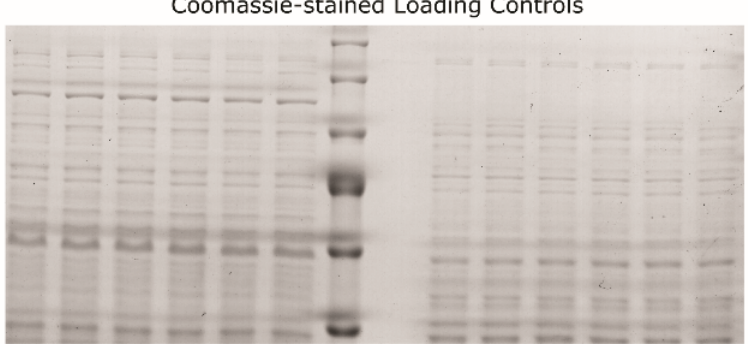

B

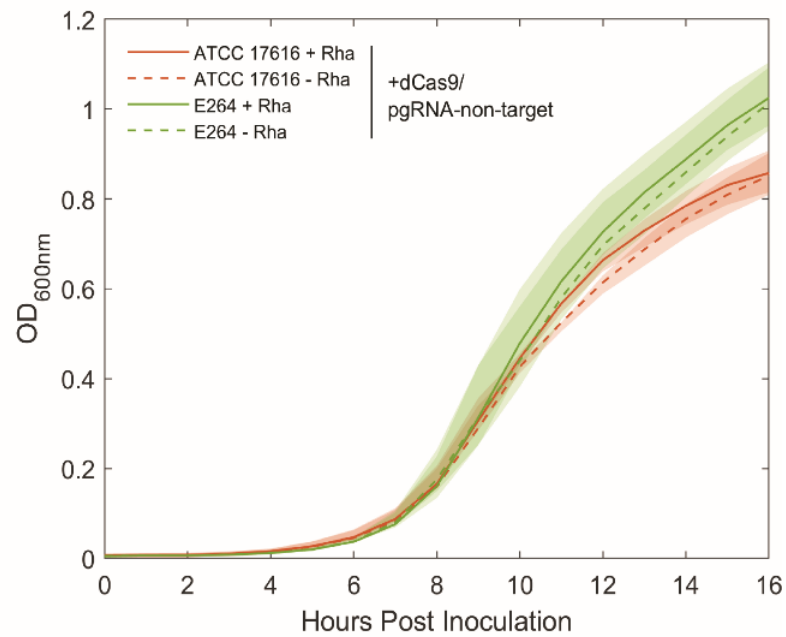

Supplemental Figure 9. dCas9 expression is detected from chromosomal expression in $B$. thailandensis E264, but poorly from B. multivorans ATCC 17616. A) Strains harbouring the codon-optimized deas 9 in the chromosome were grown at $\mathrm{OD}_{600 \mathrm{~nm}} 0.6$ then induced for three hours with the indicated concentrations of rhamnose and soluble protein was harvested. dCas9 expression was detected by probing with an $\alpha$-dCas 9 antibody. The lane labelled Cas $9+$ was loaded with $5 \mathrm{ng}$ of purified Cas9 (Genscript). Below, the protein was run in parallel on SDS-PAGE and stained with Coomassie to ensure equal protein loading. B) Growth curves of B. multivorans ATCC17616 and B. thailandensis E264 species harbouring a chromosomal copy of the codonoptimized dcas 9 and the non-genome targeting guide plasmid, pgRNA-non-target (Supplemental Table 4). 

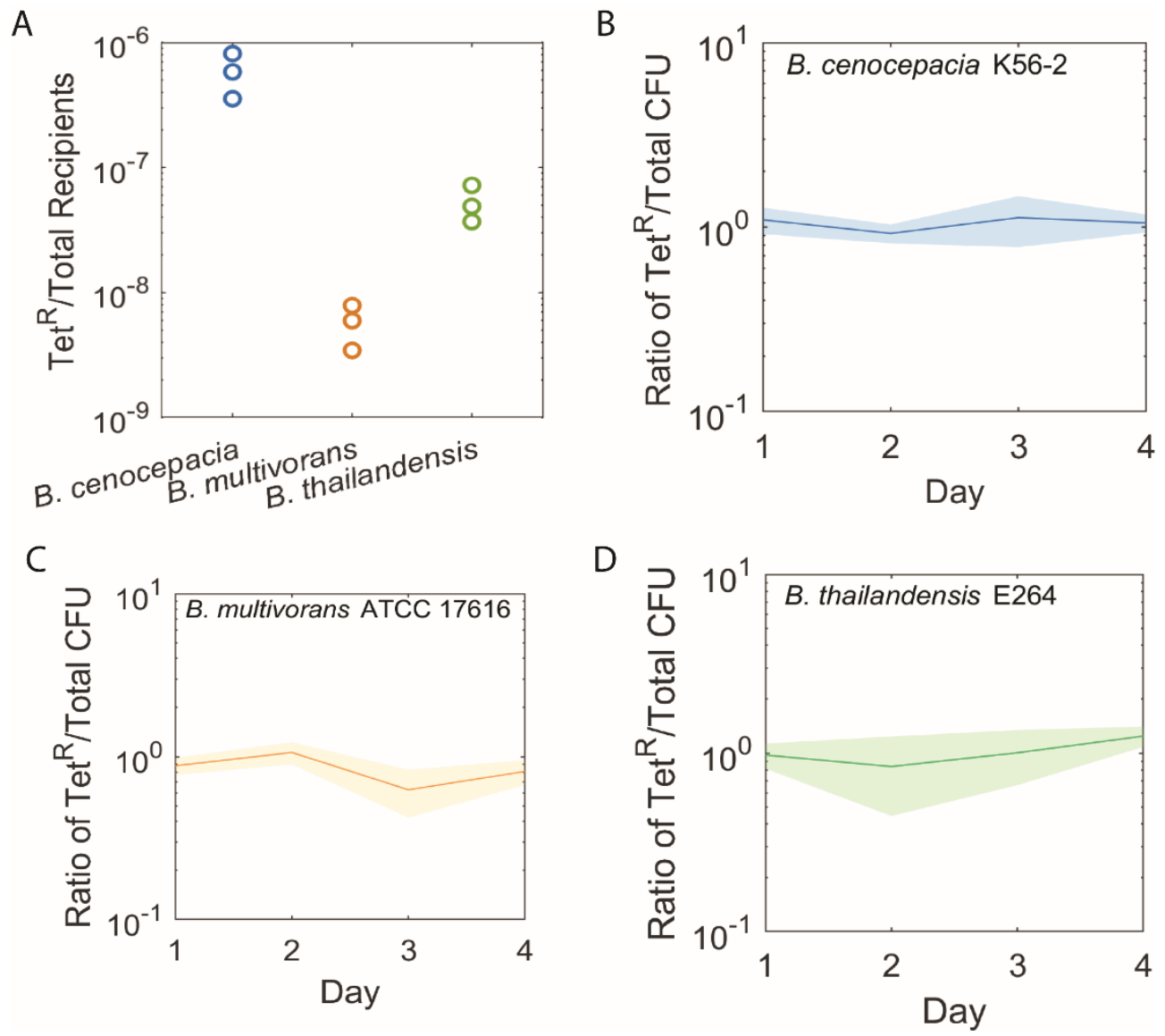

\footnotetext{
Supplemental Figure 10. pAH-CTX1-rhadCas9 integrates with variable efficiency but is maintained without antibiotic selection. A) Strains were subjected to triparental mating with pAH-CTX1-rhadCas9 as per the Materials and Methods. After mating, CFU counts were done on LB agar with $50 \mu \mathrm{g} / \mathrm{mL}$ gentamicin supplemented with and without $50 \mu \mathrm{g} / \mathrm{mL}$ tetracycline (Tet50). Ratios of CFU on the Tet50 to non-selective medium are reported. For B), C), and D) strains harbouring pAH-CTX1-rhadCas9, but not yet cleaned of the plasmid accessory genes, were passaged over four days in LB without tetracycline. For each day, the CFU counts on Tet50 and non-selective medium were determined and the ratios are reported.
} 